METODOLOGÍA Y EVALUACIÓN 



\title{
¿ES POSIBLE UNA ESTANDARIZACIÓN DE LA EVALUACIÓN DE E/LSE?
}

\author{
Martha Jurado
}

\section{(c) $(7) \ominus$}

Esta obra está bajo una licencia Creative Commons

Reconocimiento-No Comercial-Sin Obra Derivada 



\title{
¿ES POSIBLE UNA ESTANDARIZACIÓN DE LA EVALUACIÓN DE E/LSE?
}

\author{
IS STANDARDIZATION OF THE EVALUATION E/LSE POSSIBLE?
}

\begin{abstract}
RESUMEN
Este trabajo tiene como objetivo analizar las posibilidades de desarrollo de estándares internacionales de calidad en relación con la evaluación y certificación del español americano. Con base en las distintas acepciones del término "estándar", se exploran factores de índole dialectal, económica y de política lingüística que inciden en el desarrollo de dichos estándares. La exploración aporta una caracterización de las distintas posibilidades de diseño de instrumentos de evaluación, según las perspectivas de una norma ejemplar panhispánica, la selección de una variedad, o la utilización de distintas variedades en un solo instrumento. Se concluye que los factores tanto de índole dialectal como económica podrían solventarse si se tomara como punto de partida el reconocimiento del beneficio económico que representa, en general, la enseñanza del español. Dicho reconocimiento debería conducir a la instrumentación de políticas lingüísticas nacionales que, sin menoscabo de las realidades pluriétnicas, multiculturales y plurilingües que nos caracterizan, potenciaran nuestra calidad no solo de hablantes de la lengua española, sino también de enseñantes de ese patrimonio lingüístico que compartimos con millones de hablantes que habitan el vasto territorio hispanoamericano.
\end{abstract}

Martha Jurado

Palabras clave: estándares, evaluación, potencial económico, certificación, español americano.

\begin{abstract}
The aim of this article is to analyze the possibilities of developing international quality standards in relation to the assessment and certification of the American variety of the Spanish language. The starting point is the range of meanings of the term "standards", giving way to the analysis of dialectal, economic and language policy factors which have an impact on the development of such standards. The analysis brings forward the range of possibilities for designing relevant assessment instruments, in accordance with perspectives such as the adoption of a global variety of Spanish, a specific one, or the use of different dialectal varieties in the same assessment instrument. It is argued that dialectal and economic factors could be overcome if it is acknowledged that, in general, the teaching and learning of the Spanish language brings about considerable economic activity. If this premise is accepted, it should lead to the implementation of national language policies which, notwithstanding the pluriethnic, multicultural and plurilingual features of the language, would enhance our own qualities, not only in our capacity as Spanish language speakers, but also as teachers of the linguistic asset we share with the millions of people who inhabit the vast territories of Spanish-speaking America.
\end{abstract}

Key words: standards, assessment, economic potential, certification, American Spanish language.

Dra. Martha Jurado. Universidad Nacional Autónoma de México. Profesora Titular del Centro de Enseñanza para Extranjeros. México.

Correo electrónico: mjurado@unam.mx

Recepción: 15- 05- 2015

Aceptación: 19- 08- 2015 
La cultura de la gestión de la calidad tuvo su origen en el mundo empresarial a finales de la década de los 80. Se basa en un modelo conformado por factores o criterios (estándares) que se interrelacionan para lograr y mantener los mejores resultados en una empresa. Con base en el modelo, se realiza una evaluación de los diferentes elementos (valores, modelo de gestión, procesos, resultados, etc.). La información obtenida se usa para detectar las deficiencias, analizar e identificar las posibles soluciones, con el fin de implementar acciones de mejora.

La adopción de estándares en el terreno de la evaluación educativa es necesaria porque los exámenes en general, y en particular los de dominio lingüístico, tienen gran impacto en la vida de los individuos: el ingreso a una universidad, la obtención de una beca, el cumplimiento de un requisito de ciudadanía, etc. Por esta razón, la estrategia de gestión de las instituciones certificadoras se fundamentan en principios que, finalmente, resultan ser los mismos que rigen la gestión de calidad empresarial. Dichos principios son, según la European Foundation of Quality Management, el enfoque basado en procesos y hechos; enfoque hacia los resultados y hacia la satisfacción del usuario; orientación al usuario; liderazgo y coherencia con los objetivos; implicación del personal; aprendizaje, innovación y mejora continua; relaciones y alianzas mutuamente beneficiosas con el proveedor; responsabilidad social, etc. (European Foundation of Quality Management).

En este trabajo se plantea que el desarrollo de la evaluación y de la certificación apegado a estándares - particularmente en el contexto de los países de Hispanoamérica- es un fenómeno reciente que no ha alcanzado todavía su madurez debido principalmente a razones de índole dialectal, económica y de política lingüística. La gran diversidad geolectal, aunada a otros factores como las reivindicaciones de distintos grupos sociolectales y nacionales, dificultan los procesos de estandarización lingüística. Algunos de estos, como la construcción de diccionarios y de gramáticas, han prosperado de mejor manera; sin embargo, muestran un mayor rezago en áreas relativamente novedosas como la creación de instrumentos de evaluación y certificación lingüísticas. Se presentan en este documento cuatro posibilidades de desarrollo de instrumentos de evaluación que podrían dar respuesta al fenómeno de la diversidad geolectal.

En relación con los factores de índole económica, se argumenta que, pese al reconocido potencial de la lengua española como mercado, la certificación lingüística -como actividad subsidiaria a otras altamente lucrativas como la enseñanza del español y el turismo idiomático- tendrá un desarrollo a largo plazo, debido a los altos costos que implica y al desdén de las entidades públicas que podrían potenciarlo.

Como último punto se analiza la necesidad de diseñar una política lingüística para aprovechar tanto el potencial económico del español, como su coexistencia armónica y simbiótica con la riqueza que representa la realidad pluriétnica, multicultural y plurilingüe característica de varios de los países hispanoamericanos. Aunque algunos han comenzado a hacerlo desde distintos sectores, países con una fuerte presencia indígena han soslayado, por cuestiones ideológicas, las grandes ventajas que brinda la enseñanza del español y su explotación en el sector turístico.

En la primera parte de este artículo se abordan las distintas acepciones del concepto “estándar" en relación con la evaluación y la certificación en general: como conjunto de normas, como nivel de habilidad y como tipo o norma. En la segunda, se exponen los tres ejes de calidad de los exámenes de lengua: el constructo, la validez y la fiabilidad. En la tercera, se mencionan dos factores clave en la definición de estándares relacionados con la evaluación certificativa del español como lengua segunda o extranjera (E/LSE): el Marco común europeo 
de referencia para las lenguas: aprendizaje, enseñanza, evaluación (MCER) y el Sistema Internacional de Certificación del E/LE (SICELE). Finalmente, en la cuarta parte se presenta una sistematización de las posibilidades de construcción de instrumentos de evaluación que atienden la diversidad dialectal del español; asimismo se discuten algunos factores económicos que pueden potenciar su aprovechamiento y algunos otros que pueden inhibirlo.

\section{El concepto de "estándar"}

Específicamente en el contexto de la evaluación educativa, el término "estándar" se usa en varios sentidos. El primero se relaciona con las pruebas estandarizadas, es decir, en este caso los estándares son equivalentes a "conjuntos de normas": "An agreed set of guidelines which should be consulted and, as far as possible, heeded in the construction or evaluation of a test" (Alderson, Clapham y Wall, 1995, p. 236). Instituciones como la American Educational Research Association (AERA), National Council on Measurement in Education (NCME) y los Standards for Educational and Psychological Testing, utilizan el término en este sentido normativo. Así también lo maneja la Organización Internacional de Estandarización (ISO, por sus siglas en inglés), la cual lo define textualmente como: "A standard is a document that provides requirements, specifications, guidelines or characteristics that can be used consistently to ensure that materials, products, processes and services are fit for their purpose". (ISO, párr. 1).

El segundo sentido del término "estándar" se relaciona con "niveles de habilidad". Se trata de un estándar de ejecución que permite establecer niveles diferenciales de desempeño. Sirve para responder la pregunta "¿Qué nivel de competencia ha alcanzado una determinada persona?". Davies lo define como: “The skills and/or knowledge required to achieve mastery and proficiency levels leading to mastery, along with the measures that operationalize these skills and/ or knowledge and the grades indicative of mastery at each level" (Davies, 2008, en Fan, 2013, p. 3). A esta concepción corresponden los descriptores ilustrativos de desempeño plasmados en las escalas de la American Council on the Teaching of Foreign Languages (ACTFL) o en el Marco común europeo de referencia para las lenguas: aprendizaje, enseñanza, evaluación (MCER).

Las acepciones hasta aquí analizadas (conjuntos de normas y niveles de habilidad) se relacionan estrechamente con procedimientos para asegurar la calidad y, consecuentemente, con "códigos de buenas prácticas", puesto que involucran a individuos en situación de indefensión (estudiantes, jóvenes y adolescentes, de inmigrantes o de trabajadores asalariados), así como el manejo de información sensible (filiación, identificación, domicilio, desempeño académico, etc.). Se rigen por este tipo de lineamientos éticos instituciones como la International Language Testing Association (ILTA), la Association of Language Testers in Europe (ALTE), la European Association for Language Testing and Assesment (EALTA) o el English Testing Service (ETS), cuyos Standards for Quality and Fairness abarcan temas como las responsabilidades corporativas, validez, equidad, confiabilidad, diseño y desarrollo de exámenes, establecimiento de puntos de corte, administración de los exámenes, puntuación, reporte de resultados, uso de las pruebas, responsabilidades y derechos de los candidatos, etc. Todos estos documentos comparten la misma base ética:

\footnotetext{
Las fuentes epistemológicas de estos códigos de buena práctica deben buscarse en la ética y en la filosofía moral, en las que se dan esencialmente dos enfoques: uno universalista o kantiano, que favorece la confección de un conjunto de códigos aplicables a todos los partícipes y que a su vez están basados en una serie de principios. Hay que comentar que este tipo de enfoques tiende a ser dogmático, categórico e inflexible. Y otro enfoque, denominado consecuencialista, que se basa en la utilidad o en las consecuencias. Dicho de otro modo, el fin justificaría hasta cierto punto los medios. (Parrondo, 2007, párr. 21)
} 
En suma, debido en gran medida a la introducción de la gestión de calidad en el ámbito educativo, la evaluación relacionada con el diseño de instrumentos de certificación del dominio del español se concibe actualmente como “...una función de calidad técnica y ética, en la que se tiene presente la equidad como un principio implícito en la selección de situaciones evaluativas, instrumentos y técnicas de evaluación" (González-Such, Jornet-Meliá y Bakieva, 2013, p. 10). En este contexto, la creación y adopción de estándares tiene como objetivo garantizar la rendición de cuentas (accountability), la transparencia (transparency) y la equidad (fairness) (Kunnan, 2000; Shohamy, 2001; Xi, 2010).

\section{Estándares en la evaluación de lenguas}

El constructo, la validez y la fiabilidad son los tres ejes de calidad de la evaluación que han sido más ampliamente desarrollados en la bibliografía especializada (Messick, 1989, 1995; Alderson, Clapham y Wall, 1995; Bachman, 1990; Bachman y Palmer, 1996; Figueras, 2004; entre otros). El constructo es la definición explícita de aquello que se evalúa, así como de las concepciones subyacentes sobre el uso y el aprendizaje de la lengua. El constructo se concreta por escrito en un documento de especificaciones del examen.

La validez es la característica esencial de calidad de cualquier instrumento o técnica de medida/evaluación. Se refiere a la comprobación de si se mide realmente lo que pretenden medir, o bien, los resultados observados dependen de otras variables. "El término validez debe siempre ir acompañado de un para, y esta preposición está directamente relacionada con el constructo que se evalúa y con las especificaciones que lo definen" (Figueras, 2008, párr. 6).

En este sentido, se habla de un proceso continuo de validación; no se trata de una cuestión definitiva o absoluta, sino de un argumento que requerirá más o menos elaboración -según las necesidades y responsabilidades de quienes realizan o emplean el examen- y que puede ser modificado por distintas evidencias. En esencia, no se valida el instrumento, sino si los resultados son útiles para el fin para el que ha sido construido. La validación se presenta, pues, como un proceso continuo de recogida de evidencias y de información relevante, que puede incluir diversos enfoques tradicionales e innovadores de investigación evaluativa. Los procedimientos se llevan a cabo procurando determinar si hay argumentos para afirmar que las destrezas que están siendo evaluadas reflejan verdaderamente la teoría de la competencia plasmada en el constructo (Messick, 1989, 1995, 1996; Bachman, 1990; Kunnan, 2000; Alderson y Banerjee, 2002).

El tercer eje es la fiabilidad, concepto que engloba toda la tecnología psicométrica desarrollada para estimar el grado de error que afecta a las mediciones hechas con los exámenes (Muñiz et ál., 2005). Una prueba es fiable si sus resultados no varían según la hora, el día, el aula o la versión, o según el corrector o administrador. "Si contamos con un constructo claramente definido y especificado por escrito, y tenemos información suficiente para creer que nuestro examen refleja fielmente los objetivos de evaluación previstos, debemos poder garantizar la fiabilidad de los resultados" (Figueras, 2004, párr.7).

Un elemento subsidiario de calidad de la evaluación es la objetivación de la forma de valorar las respuestas de los sujetos (basadas en rúbricas bien definidas, operativas, representativas de los diversos elementos que se contemplan en el constructo). Esta objetivación es también un proceso de estandarización, que consiste en la definición de un sistema de comparación de evidencias con un estándar, y en un proceso de conformación de decisiones de acuerdo con él. En este punto, nos encontramos con una acepción más de la palabra "estándar", equivalente a "tipo" o "norma" -la primera acepción que suministra el diccionario 
de la RAE-ASALE- y, consecuentemente, con el término "estandarización", como proceso de unificación de criterios para ajustarse a dicho tipo o norma"; por ejemplo, en las pruebas de puntaje subjetivo, los acuerdos respecto a cómo se puntúa el desempeño en cada tarea.

\begin{abstract}
Los sistemas de interpretación de puntuaciones deben estar enmarcados en procesos bien establecidos y sólidamente constituidos desde análisis psicométricos sólidos. Incluyen desde las rúbricas de evaluación (elementos observacionales que se van a considerar para valorar el desempeño de los sujetos en cada tarea), hasta los estándares de interpretación y definición de los puntos de corte para asignar a cada persona evaluada su nivel de competencia de acuerdo con los estándares de calidad predefinidos. (González-Such, 2013, p. 11)
\end{abstract}

En suma, los ejes de constructo, validez y fiabilidad se articulan en una metodología estandarizada para construir los instrumentos de evaluación que constituye la garantía técnica (y ética) de uso de las evaluaciones.

\title{
3. Dos momentos clave en el desarrollo de estándares para la evaluación certificativa del español como E/LSE
}

La adopción de estándares relacionados con la evaluación certificativa del español como lengua segunda o extranjera (E/LSE) tiene dos momentos clave: 2002, aparición de la versión en español del Marco común europeo de referencia para las lenguas: aprendizaje, enseñanza, evaluación (MCER); y 2007, creación del Sistema Internacional de Certificación del E/LE (SICELE).

El Marco común europeo de referencia para las lenguas (MCER) tiene como objetivo facilitar el intercambio de información sobre conocimientos relacionados con las lenguas, mediante el establecimiento de referentes comunes. Los descriptores de nivel de actuación que en él se plantean atienden a criterios de formulación positiva, precisión, claridad y brevedad. El MCER cuenta con documentación técnica complementaria, como el Manual for relating examinations to the Common European Framework of Reference, en el cual se ofrecen pautas para relacionar o "anclar" los resultados de los exámenes con los niveles comunes de referencia, así como para demostrar cómo se ha llevado a cabo el anclaje a través de procesos de familiarización, especificación, estandarización y validación empírica. En el Manual, la estandarización es concebida como la aplicación de procedimientos que aseguran una interpretación unificada de los niveles comunes de referencia del MCER, a partir de ejemplos concretos de tareas de examen y actuaciones de alumnos. Estos procedimientos garantizan unas bases para los juicios que se toman cuando se puntúan pruebas o se elaboran tareas (Figueras, 2008).

Por otra parte, el Sistema Internacional de Certificación del E/LE (SICELE) es un organismo conformado por instituciones de educación superior del mundo hispano, que tiene como objetivo garantizar la calidad, transparencia y coherencia de los certificados expedidos por las entidades educativas a él adheridas. El SICELE supervisa el cumplimiento de una serie de parámetros de calidad en cuanto a los procedimientos de certificación del dominio de la lengua española, como el diseño, corrección, calificación, validez y fiabilidad de las pruebas; correlación de niveles de competencia; capacitación de los evaluadores, etc.

El concepto de calidad en el SICELE se entiende como el grado en el que las instituciones certificadoras del dominio del E/LSE desarrollan y administran exámenes de acuerdo con lo que los usuarios esperan de ellas. Para cumplir con sus funciones, el SICELE cuenta con un modelo de gestión de procesos que contempla la aplicación de buenas prácticas y establece estándares que permiten guiar y evaluar el grado de madurez de los sistemas. Los estándares SICELE que aparecen en la página de la organización comprenden cuatro grandes apartados: 
1. Procesos de elaboración y desarrollo de exámenes: planificación y diseño; elaboración de las pruebas; ensayos, pilotaje y calibraciones.

2. Dispositivo de gestión y administración de las pruebas de examen: gestión administrativa (inscripción y registro de candidatos, entrega de certificados o títulos), infraestructura y recursos para la administración de las pruebas, disposiciones para candidatos con necesidades especiales, selección, gestión y control de los centros de examen, logística y distribución de los materiales de examen.

3. Calificación y análisis de resultados: sistema de calificación, procesos de calificación, análisis de resultados, impacto y retroalimentación.

4. Información a los usuarios: medios, sistemas y canales de información y apoyo, veracidad de la información y equidad de la transmisión o difusión, información sobre las pruebas y muestras de actuación. Uso que pueden hacer los candidatos de la certificación, informe e interpretación de resultados, información sobre reclamos y apelaciones, divulgación de información técnica del examen.

A pesar del gran avance que representan tanto el MCER como el SICELE, la concreción de estándares aplicados a la creación de instrumentos de evaluación y certificación en lengua española continúa siendo una aspiración, debido a factores de distinta índole.

\section{Factores que inciden en el desarrollo de estándares en el contexto del español americano}

Analizaremos en esta sección los factores de índole lingüística, económica y de política lingüística que inciden en el desarrollo tanto de la enseñanza de la lengua española en general, como en particular en el desarrollo de instrumentos de evaluación y certificación apegados a estándares de calidad, en el contexto de los países hispanoamericanos.

\section{1 $\quad$ Factores de índole dialectal}

El tema de la variedad geolectal tiene una larga tradición en el ámbito de la lingüística hispánica. A pesar del discurso unitario y panhispánico de la Real Academia de la Lengua (RAE) y de que un viajero puede acostumbrarse rápidamente a las peculiaridades de las variedades nacionales del español, es evidente que -particularmente en los niveles fónico y léxico- la mayoría de los países del mundo hispánico no representa una unidad.

Como señala Moreno-Fernández (2000), en los países de América Latina hay una variedad estándar de facto (es decir una variedad mexicana, una venezolana, una chilena, una argentina, etc.) que por un lado se diferencia de la norma académica española, pero por el otro, también se distingue de las variedades no estandarizadas de esos países. Es decir, se trata de una "estandarización monocéntrica" (norma académica única prescrita por la RAE) construida sobre una realidad multinormativa (norma culta policéntrica).

Así pues, en relación con el tema de la norma lingüística, nos encontramos nuevamente con los términos "estándar" y "estandarización”. En este contexto, el significado corresponde a la tercera acepción ya registrada de "tipo" o "norma"; es decir, en el terreno lingüístico, la norma se concibe como un paradigma idealizado de lo que es "hablar bien"; mientras que la "estandarización" alude a proceso de tipificación o ajuste a dicha norma: 
Cuando una comunidad idiomática constituida por varios países -como es el caso del españoldecide dotar a su lengua de una "estandarización", es decir, decide codificar y aceptar un conjunto de normas que definan los usos correctos, por medio, básicamente, de una ortografía, una gramática y un diccionario, puede hacerlo de dos maneras: mediante una estandarización monocéntrica, que supone la aceptación universal de unas mismas normas, o por medio de una estandarización policéntrica que admitiría la convivencia simultánea de varios patrones de normas. Si nos atenemos a esta distinción, la "estandarización" del español sería monocéntrica: el mundo hispanohablante, en términos generales, acepta de forma universal unas mismas normas, unas mismas reglas. (Moreno-Fernández, 2000, pp. 76-77)

Una vez aclarado este punto -y sin entrar en el debate de las normas lingüísticas del español y de sus distintas variedades-, señalaremos que, en el terreno de la enseñanza E/LSE, la discusión sobre la diversidad dialectal se retoma en relación con la pregunta “¿qué español enseñar?”, en la cual se subsumen cuestiones como la diversidad de los orígenes geolingüísticos y sociolingüísticos de los profesores; la pluralidad de intereses de los estudiantes, y la posibilidad de utilizar el español que se aprende en distintas regiones hispánicas y en diferentes situaciones sociales.

Dado que en el ámbito de la evaluación y certificación de E/LSE priva el prurito de la estandarización, la extensión geográfica y riqueza dialectal del español, y, en concreto, la selección de la variedad lingüística más adecuada para evaluarlo, también constituye un problema para el diseño de instrumentos. Para afrontarlo, existen al menos cuatro posibilidades que pueden caracterizarse adaptando la tipología que Zimmermann (2006) propone para determinar la adopción de la variedad más apta para la enseñanza del español. En los siguientes cuadros se resumen los inconvenientes que presenta cada una de esas posibilidades:

Cuadro 1. Evaluación de acuerdo con una norma ejemplar panhispánica

\begin{tabular}{|l|l|}
\hline \multicolumn{1}{|c|}{ Descripción } & \multicolumn{1}{|c|}{ Incovenientes } \\
\hline Esta opción es defendida por lingüistas como & - Existencia de una pluralidad de normas válidas \\
Lope Blanch (1999-2001), Moreno de Alba & cultas. La exclusión de cualquiera de ellas \\
(1993, 1996) y López Morales (2005). Se trata & resultaría cuestionable. \\
de encontrar un sistema lingüístico que sea & - Dificultad para evaluar equitativamente ciertos \\
válido para todos los hablantes, porque estaría & aspectos gramaticales: flexión verbal en la $2^{a}$. \\
construido con "lo común" del habla culta de & persona (uso de vosotros y de vos), concordancia \\
tres o cuatro normas dialectales. & de los pronombres (se los dije por se lo dije), \\
& leísmo, uso de la preposición hasta, etc. \\
& - Riesgo de construir una lengua artificial con la \\
& que ningún hablante se identifique \\
\hline
\end{tabular}

Si el afán panhispánico ha rendido frutos en la creación de los diccionarios y las gramáticas de la RAE-ASALE, en el ámbito lingüístico resulta difícil de definir y en el evaluativo difícil de concretar en instrumentos. Dicha dificultad obedece principalmente a dos razones: primero, porque -como señala Demonte (2001)- los rasgos y procesos de una variedad de este tipo no configuran una totalidad social, convencional, política y lingüísticamente homogénea; sino que se encuentra siempre en proceso de reconfiguración en sus límites, contenidos, origen y criterios de selección (ya que surge por contraste y debilitación de los rasgos y procesos considerados "inapropiados", "incorrectos" o "rurales"). En segundo lugar, porque este tipo de "entelequias" lingüísticas no están descritas en ninguna parte, ni nadie se atreve demasiado, al menos en estos momentos de corrección política, a pronunciarse sobre qué variedad geográfica o social ha de considerarse como más prestigiosa y por tanto, habría de constituir la base de dicha variedad panhispánica. 
Cuadro 2. Utilización de diversas variedades en un solo instrumento

\begin{tabular}{|c|c|}
\hline Descripción & Inconvenientes \\
\hline $\begin{array}{l}\text { Elaboración de un solo instrumento que } \\
\text { contenga equilibradamente muestras } \\
\text { de lengua de tres o cuatro normas } \\
\text { dialectales, para las habilidades receptivas } \\
\text { (comprensión auditiva y comprensión de } \\
\text { lectura). Para las habilidades productivas } \\
\text { (expresión oral y escrita), se aceptaría } \\
\text { indistintamente el habla culta de cualquier } \\
\text { norma. }\end{array}$ & $\begin{array}{l}\text { Dificultad para encontrar a los } \\
\text { especialistas creadores en todas las } \\
\text { normas utilizadas y en todos sus } \\
\text { niveles lingüísticos. } \\
\text { Dificultad para capacitar a los } \\
\text { aplicadores, quienes deberían tener } \\
\text { un amplio criterio y conocimiento } \\
\text { vasto de las distintas variedades. } \\
\text { Injusticia que implica el exigir a los } \\
\text { candidatos el conocimiento (aunque } \\
\text { sea pasivo) de distintas variedades } \\
\text { geolectales, que algunas veces, ni el } \\
\text { profesor mismo conoce. }\end{array}$ \\
\hline
\end{tabular}

La segunda posibilidad se plasma en el terreno didáctico en el llamado "español mundial" (Beaven y Garrido, 2000), que consiste en la exposición de los alumnos a las distintas variedades del español desde los niveles iniciales. Este modelo comprende como uno de sus componentes fundamentales el desarrollo de la competencia intercultural; es decir, de la habilidad para desarrollar un sistema interpretativo de referencias culturales para estructurar el conocimiento implícito y explícito, con el fin de acceder a los significados, creencias y prácticas culturales de otras comunidades de hablantes. Aunque en el aula es posible adoptar como método didáctico el español mundial, con su concomitante componente intercultural, en el terreno de la evaluación su eficacia está todavía por comprobarse. Para 2016 está programado el lanzamiento del Sistema Internacional de Español como Lengua Extranjera (SIELE), un examen elaborado por el Instituto Cervantes, la Universidad de Salamanca y la Universidad Nacional Autónoma de México, que medirá desde el Nivel A1 hasta el C1 del MCER y en cuyas pruebas receptivas se mezclan textos pertenecientes a las normas cultas de distintos países del mundo hispánico.

Cuadro 3. Selección de la variedad más apta con base en criterios fundamentados

\begin{tabular}{|c|c|}
\hline Descripción & Inconvenientes \\
\hline $\begin{array}{l}\text { Algunos criterios que se deben tomar en cuenta: } \\
\text { Cuantitativos: } \\
\text { Número de hablantes } \\
\text { Cualitativos: } \\
\text { 1. Producción literaria. } \\
\text { 2. Producción científica. } \\
\text { 3. Presencia en medios masivos (incluyendo Internet). } \\
\text { 4. Infraestructura para publicaciones. } \\
\text { 5. Desarrollo de la lingüística en el país. } \\
\text { 6. Desarrollo de la lingüística aplicada y de la } \\
\text { didáctica de la lengua. } \\
\text { 7. Producción de materiales didácticos. } \\
\text { 8. Número suficiente de profesores. } \\
\text { 9. Apoyos institucionales para favorecer el } \\
\text { conocimiento y difusión de la lengua. }\end{array}$ & $\begin{array}{l}\text { - Existen asimetrías fuertes en todos los órdenes, } \\
\text { entre un centro de poder lingüístico como } \\
\text { España y el resto de los países hispanohablantes. } \\
\text { La norma ibérica sería hegemónica con los } \\
\text { consecuentes reclamos de equidad por parte del } \\
\text { resto de los países hispanohablantes. } \\
\text { Dificultad del resto de los países } \\
\text { hispanoamericanos para alcanzar estos } \\
\text { estándares en un corto plazo. }\end{array}$ \\
\hline
\end{tabular}


La tercera posibilidad se ha materializado (en gran medida, puesto que en la evaluación de los niveles superiores se incorporan textos de otras variedades distintas a la castellana) desde hace varias décadas, en los Diplomas de Español como Lengua Extranjera (DELE) creados por la Universidad de Salamanca y administrados por el Instituto Cervantes de España. Debido a que cumple con los nueve criterios de calidad enumerados en el Cuadro 2, constituyen hasta la fecha los exámenes con mayor prestigio y aceptación por parte de los usuarios interesados en certificar su dominio lingüístico.

Cuadro 4. Reconocimiento de instrumentos elaborados en diversas variedades

\begin{tabular}{|l|l|}
\hline \multicolumn{1}{|c|}{ Descripción } & \multicolumn{1}{c|}{ Inconvenientes } \\
\hline $\begin{array}{l}\text { Elaboración de varios instrumentos } \\
\text { correspondientes a diversas variedades, que sean } \\
\text { acreditados y reconocidos recíprocamente. }\end{array}$ & $\begin{array}{l}\text { Requiere del concurso de varias instancias } \\
\text { oficiales y del cumplimiento de estándares } \\
\text { difíciles de alcanzar en un plazo relativamente } \\
\text { corto. }\end{array}$ \\
\hline
\end{tabular}

Esta opción posibilita que cada país del mundo hispánico desarrolle sus propios instrumentos de evaluación y que estos sean reconocidos oficialmente -gracias a la certificación otorgada por un organismo internacional- por una red de instituciones educativas y por tanto, por muchas otras entidades, para distintos fines relacionados con la evaluación del dominio lingüístico de un candidato. Esta es la posibilidad que encarna el Sistema Internacional de Certificación del E/LE (SICELE). Este organismo supranacional ha representado para varios países hispanohablantes un gran avance en el desarrollo de instrumentos de evaluación apegados a estándares de calidad.

En suma, de estas cuatro alternativas para encarar el reto que representa la diversidad dialectal del español en relación con el desarrollo de instrumentos de evaluación, hasta la fecha ha sido predominante la tercera (la selección de la variedad más apta con base en criterios fundamentados). Ante la hegemonía de la variedad castellana, a los países hispanoamericanos corresponde la responsabilidad de hacer uso de las condiciones que brinda el SICELE, para reafirmar la presencia de sus respectivas variedades lingüísticas y aprovechar el potencial que representa, en general, la enseñanza de la tercera lengua más hablada en el mundo. Las condiciones formales, tecnológicas y de cooperación internacional están dadas; se trataría de sacar provecho de ellas para crear instrumentos audaces, multidimensionales y respetuosos de la diversidad dialectal.

\subsection{Factores de índole económica}

Desde una perspectiva económica, la lengua es un componente esencial del capital humano y social de una comunidad. Según, Jiménez (2009), se estima que un 15\% del producto interno bruto (PIB) de un Estado está vinculado con la lengua. Su importancia económica se mide teniendo en cuenta factores como el número de hablantes, la extensión geográfica, el número de países en los que tiene rango de oficial y el índice de desarrollo humano de sus hablantes (que combina nivel educativo, esperanza de vida y renta per cápita).

Los economistas distinguen al menos tres funciones económicas de la lengua:

a) La lengua como soporte de la comunicación y la creación. Es un elemento central del sector cultural que ha cobrado una gran importancia en la economía internacional con el crecimiento de las industrias culturales: la literatura, el teatro, el cine, la música, los medios de comunicación, la producción científica e intelectual y la educación. 
b) La lengua como idioma para el comercio. La lengua y la cultura facilitan las inversiones internacionales. Este factor reduce los costos de transacción (formación, información y negociación) y acorta la distancia psicológica entre los agentes económicos.

c) La lengua como mercado. Se refiere a la enseñanza del idioma y a las actividades mercantiles asociadas a ella: servicios lingüísticos, la enseñanza como lengua extranjera, el turismo idiomático, las ediciones para la enseñanza asociadas a esa actividad, la certificación lingüística y las tecnologías de la lengua (desarrollo de herramientas y recursos informáticos relacionados con la lengua).

El desplazamiento cuya motivación principal es aprender un idioma se denomina "turismo idiomático". Las instituciones oficiales del sector turístico lo definen como "una modalidad de viajes de estudio y ocio que buscan las personas para aprovechar las vacaciones aprendiendo o mejorando su competencia en una lengua..." (Castillo, 2011). El español es un recurso turístico con gran potencial (como lo demuestran los 858000 turistas que, según datos del Instituto Cervantes (2015), visitaron España en 1914 por motivos académicos, muchos de ellos relacionados con el idioma). Una apuesta decidida por esta opción -en conjunto con la acción de varios organismos y con el impulso a otros tipos de turismo (cultural, ecológico, de aventura, etc.)- podría contribuir a reafirmar el rol preponderante del español en nuestros países $\mathrm{y}$, consecuentemente, a mejorar su imagen internacional.

Una de las medidas necesarias para potenciar el turismo idiomático es la creación y diversificación de certificados con respaldo público que garanticen la calidad de los centros que imparten la enseñanza del español para extranjeros. Los turistas idiomáticos podrían culminar sus estancias de estudio en cualquier institución pública o privada de enseñanza del español presentando exámenes expedidos por instituciones acreditadas por organismos como el SICELE.

Sin embargo, la certificación lingüística es uno de los rubros de más difícil desarrollo, principalmente por el alto costo que representa crear y mantener uno (o varios) certificados o sistemas de certificación apegados de manera estable a los parámetros de calidad, lo cual se relaciona asimismo con factores como:

La poca exigencia de los usuarios, que no tienen suficiente información sobre los objetivos, cualidades y usos de los distintos certificados.

La poca profesionalización de aquellos que diseñan, elaboran, administran o corrigen pruebas de certificación.

El poco interés de políticos e instituciones responsables en un trabajo riguroso que resulta costoso y que por lo tanto se tiende a dejar en manos de docentes voluntariosos. (Figueras, 2004, párr. 12)

La potenciación por parte de los países hispanoamericanos de esta actividad subsidiaria del turismo idiomático, y relegada hasta la fecha a los esfuerzos de "docentes voluntariosos", requeriría del diseño y puesta en práctica de políticas lingüísticas que reconocieran el valor de la lengua como recurso económico.

En suma, un impulso integral a la enseñanza del español y a sus actividades concomitantes, como la certificación lingüística, convertirían a este bien intangible -que compartimos en un territorio contiguo con casi 500 millones de hablantes- en un poderoso motor, no contaminante, no depredador ni de nuestros recursos ni de nuestro patrimonio cultural, sino enriquecedor del intercambio social, cultural, educativo y, por supuesto, económico. 


\title{
4.3 Factores de política lingüística
}

Señales de un cambio de rumbo en cuanto a la falta de interés hacia el potencial económico de la lengua se vislumbran en algunos países hispanohablantes del Continente. Por ejemplo, los países del Mercosur han celebrado ya cinco congresos sobre turismo idiomático (Córdoba, 2010; Valparaíso, 2011; Bariloche, 2012; Sao Paulo, 2013; Buenos Aires, 2014). Los organizadores de dicho evento describen de esta manera los beneficios que esta actividad acarrea:

\begin{abstract}
Cuando vienen aquí saborean nuestra cultura, establecen vínculos con las familias con las que se alojan, gastan mucho más que un turista normal en ocio', asegura Marcelo García, presidente de la asociación de centros de idiomas de Argentina, que desde hace cuatro años organiza el congreso internacional de turismo idiomático, lo secunda: 'Empiezan por el idioma, pero luego les acaba enganchando el tango, el jamón, la música, la literatura... Son personas que se involucran con la comunidad local mucho más que otro visitante'. (Peiro, 2015, párr. 4)
\end{abstract}

Por otra parte, en 2010, la Presidencia de Colombia incluyó en el documento titulado Buen Gobierno para la prosperidad democrática. 110 iniciativas para lograrla, un punto que alude expresamente al impulso de la lengua como actividad económica, el cual a la letra dice:

61. APRENDA EL MEJOR ESPAÑOL DEL MUNDO. Con base en nuestra bien ganada reputación de hablar el mejor español del mundo, uniremos la fuerza y la reputación del Instituto Caro y Cuervo con las universidades y la empresa privada, para convertir a Colombia en el mejor destino en América Latina para aprender español como segunda lengua. (2010, p. 34)

Desafortunadamente, en otras latitudes del Continente, la falta de interés de los políticos y su consecuente carencia de desarrollo de políticas lingüísticas nacionales que involucren el aprovechamiento de español como recurso económico obedecen a razones exógenas que, en casos como el de México (el país con mayor número de hispanohablantes en el mundo), son difícilmente superables en un corto plazo. Según Lara (2006), este vacío se debe al papel inhibidor de la reflexión que tiene la ideología nacional, así como a las complejas características del multilingüismo y la multiculturalidad mexicanos.

El mencionado lingüista señala que la ideología nacional mexicana tiene como uno de sus pilares "el papel simbólico del pasado prehispánico, que asienta los fundamentos de legitimidad nacional mexicana en unos orígenes míticos, cuidadosamente elaborados desde finales del siglo XVIII" (Lara, 2006, p. 491). Este enaltecimiento mítico y demagógico oblitera la raíz hispanohablante de México y consecuentemente, su orgullosa apropiación por parte de las instituciones culturales, políticas y sociales que, paradójicamente, la utilizan como medio de comunicación oficial:

...la ideología nacional se manifiesta básicamente contradictoria, pues por un lado, su indigenismo inhibe el reconocimiento de la lengua española como el principal constituyente del Estado mexicano, con la consecuencia de que no se asumen plenamente las necesidades de su educación, las necesidades de protección jurídica de los hispanohablantes mexicanos en los ámbitos del comercio internacional, las comunicaciones con el extranjeros y los derechos del consumidor, y la necesidad de una política activa, concertada con los demás países de lengua española, para conservar el papel internacional de la lengua en el mundo actual, tan sometido al "pensamiento único" angloamericano. (Lara, 2006, p. 493)

Con base en la situación mexicana, podríamos aventurar la generalización de que países como Perú y Bolivia difícilmente podrán superar el fuerte factor inhibitorio que, para el aprovechamiento del potencial económico del español, representa la fuerte presencia 
demográfica y cultural de los grupos indígenas. Es decir, la gran riqueza pluriétnica, multicultural y plurilingüe de su demografía constituye un atractivo turístico vigoroso, excepto, paradójicamente, para el turismo idiomático ligado con la lengua española.

\section{Conclusiones}

Una vez exploradas las distintas acepciones del término "estándar" (conjuntos de normas y niveles de habilidad, tipo o norma), así como los factores de índole dialectal, económica y de política lingüística que inciden en el desarrollo de instrumentos de certificación lingüística apegados a estándares de calidad, estamos en posibilidad de responder a la pregunta que da título a este artículo ¿Es posible una estandarización de la evaluación de E/LSE?

La respuesta contundente es que dicho proceso de estandarización no solo es posible, sino necesario. Para que los países hispanoamericanos alcanzaran el objetivo de contar con exámenes creativos, multidimensionales, respetuosos de las distintas variedades lingüísticas del español, metodológicamente rigurosos y adecuados a las distintas necesidades, sería necesario el trabajo conjunto de investigadores, inversionistas, sector educativo y universidades públicas, en el diseño de una política interior que prestigiara tanto al español, como a las lenguas originarias; respetuosa de la multiculturalidad; basada en los principios de la democracia (equidad, rendición de cuentas y transparencia) y, sobre todo, que fortaleciera el desarrollo del E/LSE como opción válida de enseñanza. Es decir, una política lingüística que nos impulsara a apropiarnos de nuestra lengua y a asumirla como el medio para ejercer nuestra ciudadanía y nuestra profesión con los estándares de calidad que exige el mundo globalizado del siglo XXI.

\section{Bibliografía}

Alderson, J. Ch., Clapham, C. y Wall, D. (1995). Language Test Construction and Evaluation. Cambridge: Cambridge University Press.

Alderson, J. Ch. y Banerjee, J. (2002). Language testing and assessment (Part 2). Language Teaching. 35 (2), 79-113.

Association of Language Testers of Europe (ALTE). (1994). The ALTE code of practice. http:// www.alte.org/attachments/files/code_practice_eng.pdf [Consulta 15 de mayo de 2015].

Association of Language Testers in Europe (ALTE) y Council of Europe. Language Policy Division. (2011). Manual for Language Test Development and Examining. https://sites. google.com/site/mltdees/ [Consulta 15 de mayo de 2015].

Bachman, L. (1990). Fundamental considerations in language testing. Oxford: Oxford University Press.

Bachman, L. y Palmer, A. (1996). Language testing in practice: Designing and developing useful language tests. USA: Oxford University Press.

Beaven, T. y Garrido, C. (2000). El español tuyo, el mío, el de aquél... ¿Cuál para nuestros estudiantes? Actas del XI Congreso Internacional de ASELE. Zaragoza. http://cvc. cervantes.es/ensenanza/biblioteca_ele/asele/asele_xi.htm [Consulta 15 de abril de 2011].

Castillo, C. (2011). La conceptualización de los segmentos turísticos en Andalucía: una breve aproximación. TURyDES. 4 (10). http://www.eumed.net/rev/turydes/10/ccr.htm [Consutla 15 de mayo de 2015]. 
Consejo de Europa. (2002). Marco común europeo de referencia para las lenguas: aprendizaje, enseñanza, evaluación. MECD, Instituto Cervantes y Anaya. http://cvc.cervantes.es/ obref/marco [Consulta 15 de mayo de 2015].

Council of Europe. Language Policy Division. (2009). Manual for relating Language Examinations to the Common European Framework of Reference for Languages (CEFR). http://www.coe.int/T/DG4/Linguistic/Manuel1_EN.asp\#Manual [Consulta 15 de mayo de 2015].

Demonte, V. (2001). El español estándar (ab)suelto. Algunos ejemplos del léxico y la gramática. II Congreso Internacional de la Lengua Española. http://eldiae.es/wp-content/ uploads/2014/07/El-espa\%C3\%B1ol-lengua-viva-2014.pdf [Consulta 15 de mayo de 2015].

English Testing Service (ETS). (2002). Standards for Quality and Fairness. https://www.ets. org/s/about/pdf/standards.pdf [Consulta 15 de mayo de 2015].

European Foundation of Quality Management (EFQM). (s.f.). http://www.efqm.org/ [Consulta 15 de mayo de 2015].

European Association for Language Testing and Assessment (EALTA). (2006). EALTA guidelines for good practice in language testing and assessment. http://www.ealta. eu.org/documents/archive/guidelines/English.pdf [Consulta 15 de mayo de 2015].

Fan, J. (2013). Developing professional standards for EFL testing in China: Contexts, considerations and challenges. [pdf.]. http://www.britishcouncil.cn/sites/britishcouncil. cn/files/topic_2_-_fan_jinsong_0.pdf [Consulta 15 de mayo de 2015].

Figueras, N. (2004). Estándares y calidad en la elaboración y administración de pruebas y exámenes. Criterios mínimos para el reconocimiento y la comparabilidad. III Congreso Internacional de la Lengua Española. http://congresosdelalengua.es/ rosario/ponencias/internacional/figueras_n.htm [Consulta 15 de mayo de 2015].

Figueras, N. (2008). El MCER, más allá de la polémica. MONOGRÁFICOS marcoELE, 7. http:// marcoele.com/descargas/evaluacion/03.figueras.pdf [Consulta 15 de mayo de 2015].

González-Such, J., Jornet-Meliá, J. M. y Bakieva, M. (2013) Consideraciones metodológicas sobre la evaluación de la competencia oral en L2. REDIE - Revista electrónica de investigación educativa. 15 (3). http://redie.uabc.mx/index.php/redie/article/ viewFile/545/836 [Consulta 15 de mayo de 2015].

Instituto Cervantes. (2015). El español: una lengua viva. Informe 2014. http://eldiae.es/ wp-content/uploads/2014/07/El-espa\%C3\%B1ol-lengua-viva-2014.pdf [Consulta 15 de mayo de 2015].

International Organization for Standarization (ISO). (s.f.). http://www.iso.org/iso/home/ standards.htm [Consulta 15 de mayo de 2015].

Jiménez, J. C. (2009). El poder de compra del español en el mundo. Revista de Occidente. 335, 21-36.

Kunnan, A. (2000). Fairness and Validation in Language Assessment: Selected Papers from the 19th Language Testing Research Colloquium. Orlando, Florida: Cambridge University Press. 
Lara, L. F. (2006). ¿Por qué no hay una política lingüística en México?. Por R. Terborg y L. García-Landa (Eds.). Los retos de la planificación del lenguaje en el siglo XXI. (489500). México: UNAM-CELE.

Lope-Blanch, J. M. (1999). Español de México frente a español de España. Español Actual. 71, 7-11.

Lope-Blanch, J. M. (2001). La norma lingüística hispánica. II Congreso Internacional de la Lengua Española. http://www.cvc.cervantes.es/obref/congresos/valladolid/ponencias/ unidad_diversidad_del_espanol/1_la_norma_hispanica/lope_j.htm [Consulta 15 de mayo de 2015].

López-Morales, H. (2005). La aventura del español en América. Madrid: S.L.U. Espasa.

Messick, S. (1989). Test validity: a matter of consequences. Social Indicators Research. 45 (1-3), 35-44.

Messick, S. (1995). Standards of Validity and the Validity of Standards in Performance Assessment. Educational Measurement: Issues and Practice. 14 (4), 5-8.

Messick, S. (1996). Validity and Washback in Language Testing. ETS Research Report Series. (1), 1-18.

Moreno de Alba, J. G. (1993). Dialectología y enseñanza del español como lengua extranjera. Estudios de Lingüística Aplicada. (17), 7-17.

Moreno de Alba, J. G. (1996). Sobre la divulgación del español en el mundo. Nuevas minucias del lenguaje. (338-341). México: FCE.

Moreno-Fernández, F. (2000). Qué español enseñar. Madrid: Arco/Libros (Cuadernos de didáctica del español/LE).

Muñiz, J., Fidalgo, A. M., Cueto, E., Martínez, R. y Moreno, R. (2005). Análisis de los ítems. Madrid: La Muralla.

Parrondo, J. R. (2007). El compromiso con la calidad en la evaluación y certificación. IV Congreso Internacional de la Lengua Española. http://congresosdelalengua.es/ cartagena/ponencias/seccion_3/36/parrondo_juan_ramon.htm [Consulta 15 de mayo de 2015].

Peiro, P. (2015, 24 de abril). El turismo idiomático del español crece en todo el mundo. El país. http://cultura.elpais.com/cultura/2015/04/24/actualidad/1429890190_812984. html [Consulta 15 de mayo de 2015].

Presidencia de Colombia. (2010). Buen Gobierno para la prosperidad democrática. 110 iniciativas para logarla. http://www.mineducacion.gov.co/1621/articles-243986_ archivo_pdf_109iniciativas.pdf [Consulta 15 de mayo de 2015].

Sistema Internacional de Certificación del Español como Lengua Extranjera (SICELE). (s.f.). Estándares de calidad. https://sites.google.com/a/sicele.org/sicele/politica-de-calidad/ estandares-sicele [Consulta 15 de mayo de 2015].

Shohamy, E. (2001). Democratic assessment as an alternative. Language Testing. 18 (4), 373-391.

Xi. (2010). How do we go about investigating test fairness. Language testing. 27 (2), 147-170. 
Zimmermann, K. (2006). La selección de una variedad nacional como variedad principal para la enseñanza del español como lengua extranjera: problemas de la política lingüística de lenguas extranjeras y de la política lingüística exterior en el mundo hispánico. Por $\mathrm{R}$. Terborg y L. García (Coords). Los retos de la planificación del lenguaje en el siglo XXI. (Vol. 2.). (565-590). México: UNAM. 
